\title{
A Case Report on Blood in Breastmilk: Safety Issues and Islamic Ruling
}

\author{
NA Jamani ${ }^{1}$, Hasbullah Mohamad ${ }^{2}$ \\ ${ }^{1}$ Department of Family Medicine, Kulliyyah of Medicine, ${ }^{2}$ Department of Fundamental \& Inter-Disciplinary \\ Studies International Islamic University Malaysia, Kuantan Pahang.
}

\section{ABSTRACT}

This case study demonstrates a 33-year old nursing mother who had noticed that her breastmilk had traces of blood giving the appearance of a strawberry coloured milk while expressing for her infant. This is an uncommon encounter but important issue to raise concern among Muslim nursing mothers in terms of medical safety and Islamic ruling of the standpoint of legal theorists (usul al-figh) and legal maxim (qawai'id fiqhiyyah).

Keywords: blood, breast milk, breastfeeding, Islamic ruling on blood-tinged breastmilk, usul al fiqh

\section{INTRODUCTION}

Blood in breastmilk is an uncommon encounter for nursing mothers. It can raise anxiety and concern from the medical health and Islamic perspectives to Muslim mothers whether it is safe to consume by their infants. The presence of blood can be overwhelming to mothers leading to early cessation of breastfeeding. We describe a nursing mother who presented with blood stained breastmilk, along with a discussion and review of literature on its safety and Islamic ruling dilemma.

\section{CASE REPORT}

A 33-year old woman, Para 1 complained of blood stained breastmilk while expressing her breastmilk via mechanical breast pump from her left breast at her workplace for one day duration. She has no known medical illness. She has been exclusively breastfeeding her baby for the past 6 months. She also complained of slight nipple pain while expressing milk on the left breast and noticed that a segment of her breast was swollen and red. However, there were no other associated symptoms such as nipple discharge, breast lump or fever prior to that. There were also no other breastfeeding problems encountered before. She fed directly her child at home and expressed about 4 times per day during work with a mechanical double breast pump for 10-15 minutes per session. There was no significant past medical history nor history of malignancy in the family.

Clinical examination showed that she was afebrile and had normal vital signs. Breast examination showed that there was a small abrasion over the lower outer quadrant of the nipple on the left

NA Jamani,

Department of Family Medicine,

Kulliyyah of Medicine,

International Islamic University Malaysia,

Kuantan Campus.

Emai:minaida@iium.edu.my breast in which was tender to touch. There was also a localized tenderness at the outer lower quadrant of the left breast which was mildly swollen. No erythematous skin changes or lump were noted. A pink -coloured milk was seen when the nipple is expressed. The right breast and axillary region were normal. Her full blood count was normal. Breastmilk analysis showed red blood cells and foamy macrophages with no malignant cells. Culture and sensitivity of the milk revealed no growth.

She was prescribed lanolin ointment to heal the nipple crack and antibiotic for mastitis. Breastfeeding was reinforced to be continued during the episode with hand expression rather than mechanical expression. However, despite the reassurance, the mother discarded the blood stained milk and only breastfed on the other breast. A gradual return of breastmilk colour to white colour was seen in two days. An ultrasound of the breast after a week showed echogenicity related to lactation with no other abnormality seen.

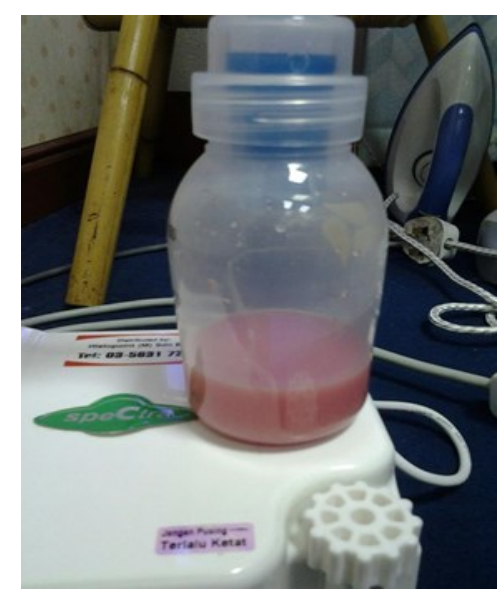

Figure 1: The 'strawberry milk'- blood stained breastmilk 


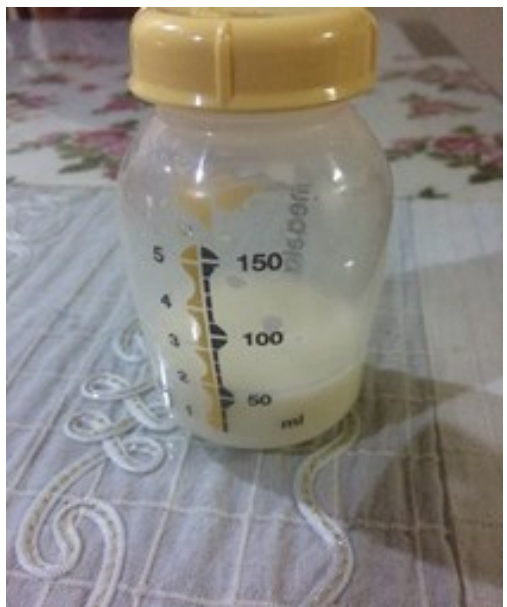

Figure 2: Breastmilk colour that has returned to its usual colour

\section{DISCUSSION}

Any change of colour in the breastmilk can produce anxiety and concern to breastfeeding mothers which possibly can lead to early cessation of breastfeeding itself. It is a rare phenomenon that is encountered both by the nursing mothers and health care professionals which may trigger an alarming response to multiple investigations. It is estimated that the prevalence of blood-stained milk is $0.1 \%{ }^{1}$

There are many cited causes that are associated with blood-stained breastmilk. The common ones in the literature are trauma, nipple crack, mastitis, abscess, benign papilloma and even breast cancer. The timing of blood stained breastmilk is important in order to rule out the causing factor. ${ }^{2,3}$

\section{Causes of blood -stained breastmilk}

Mastitis is a common problem of breastfeeding mothers. Mastitis is defined as inflammation of the breast which may or may not involve an infection process. ${ }^{4}$ It is clinically characterized by fever and a tender, warm, swollen wedge shaped area of the breast. A study done by Fetherston found that blocked ducts, attachment difficulties and history of previous mastitis are predictive risk factors for mastitis. ${ }^{5}$ Since it is a clinical diagnosis, therefore laboratory investigation is not routinely needed.

A culture and sensitivity of the breast milk is only required when it does not respond to appropriate antibiotics within 2 days, a relapse of mastitis, a nosocomial mastitis or atypical presentation. ${ }^{6}$ In view that mastitis may happen without infective process, not all cases require antibiotic. ${ }^{4}$ Effective removal of breast milk is crucial in overcoming milk stasis and healing nipple crack in which can act as an entry point for bacteria leading to mastitis. Antibiotic that is suitable for treating mastitis is penicillin group and cephalosporin. ${ }^{4,7}$

In addition, rusty pipe syndrome is another causal factor which can cause a blood -stained breastmilk.
It is a self -limited benign condition where hypervascularization of the alveoli of the breast gets easily traumatized during late pregnancy or in the early days of lactation. ${ }^{1,8,9}$ It is a painless condition that is often resolved between 3 to 5 days without any treatment. ${ }^{8}$ However, in some reported cases it can persist up to 8 weeks postpartum with complete resolution. ${ }^{10}$ In a study done by Merlob et. al shows that this condition occurs more commonly in primigravida mothers and mainly happens in bilateral breast. ${ }^{1}$ Investigation and treatment are not needed for this condition.

Trauma to the nipple or nipple crack can also cause blood-stained breast milk. Nipple crack usually happens during the early days of lactation but may occur at any time throughout the lactation period. A study done in New York and Italy showed high prevalence of up to $32-35 \%$ of mother experiencing nipple crack especially during the early days of lactation. ${ }^{11}$ Factors associated with nipple crack are poor breastfeeding technique, breast engorgement and bottle feeding to the infant. ${ }^{11}$ Poor breastfeeding technique in which includes poor attachment and positioning of the infant has been documented as a cause of nipple crack. ${ }^{2}$

Nevertheless, the use of feeding bottle may alter the infant's sucking techniques between the breast and the bottle, which eventually leads to nipple trauma and nipple crack which in turns becomes an entry point for bacteria to set in causing mastitis. ${ }^{11,12}$ The association of breast engorgement and nipple crack is that in breast engorgement, the breast becomes oedematous causing difficulty to latch the baby which causes nipple trauma thus leading to mastitis. ${ }^{13}$

Other cause for blood -stained breastmilk is intraductal papilloma. It is a benign growth that projects into the lumen of the ducts that bleeds as it erodes. ${ }^{14,15}$ The nipple discharge is usually prolonged and unilateral. Mothers who are suspected to have intraductal papilloma should undergo further investigation such as ultrasound and mammogram. Surgical intervention is required for this condition either microdochectomy or subareolar duct excision.

Presence of blood-stained breastmilk could also signal a sinister condition such as breast cancer. Breast cancer in pregnancy and during lactation is not uncommon. The prevalence is estimated to be 1- 3\%. ${ }^{10,16}$ The most reported symptoms for breast cancer during lactation is a painless palpable mass or unresolved recurrent mastitis at the same site. Rejection by the infant of the diseased breast could also point to an underlying malignancy. ${ }^{17-19}$

However, breast cancer during pregnancy and lactation usually present late due to the difficulties to detect any abnormalities because of the hormonal changes effect. ${ }^{14,18}$ Helewa et. al concluded that unresolved obstructed ducts with conservative treatment within 72 hours may also be 
the presenting symptoms by nursing mothers for breast cancer. ${ }^{16}$ Therefore, it is encouraged for breastfeeding mothers to perform a breast self examination and to seek professional help for further evaluation.

\section{Safety of ingesting blood- stained breastmilk}

Nursing mothers are usually concerned regarding blood stained breastmilk whether it is safe to be consumed by their infants. The concerns are made worst when some online advices vary from discarding the breastmilk and discontinuing breastfeeding to continuing breastfeeding. ${ }^{20-22}$ Among health care professional itself, the decision is mixed between discarding the milk or to be given to the infant. ${ }^{23}$

The concern raised is that blood-stained breastmilk may result in gastrointestinal disturbance such as vomiting or regurgitation and unnecessary investigation to be carried out especially in premature babies where necrotizing enterocolitis is a common complication. A survey done by Phelps et. al among neonatal intensive unit staffs found that only $25 \%$ would suggest to feed a moderately blood-stained breastmilk to the neonates. ${ }^{23}$

Interestingly, a case reported by Faridi et. al and Barco et. al found that the infant was able to tolerate the blood-stained breastmilk without any complication. ${ }^{8,24}$ Thus, this shows that it is considered harmless to feed an infant with a bloodstained breastmilk and there is no need to substitute with artificial milk during this period if the infant is able to tolerate the blood -stained breastmilk. On the contrary, further studies on the safety issue of feeding blood-stained breastmilk and the perceived problems is required in order to provide a scientific evidence and best practice on this matter.

In view that breastfeeding is beneficial for the mother-baby dyads, it is important that breastfeeding should be continued despite the blood-stained breastmilk. In most lactation textbook, it is recommended that feeding bloodstained breastmilk is tolerated well without much complication. ${ }^{25,26}$ Therefore, proper counselling is crucial to encourage these mothers to successfully breastfeed their infants even in challenging situation.

\section{Islamic Ruling From Usul al-Figh (Legal Theorist) and Qawa'id Fiqhiyyah (Legal Maxim) Perspective}

Islam is unique among the religions and civilizations the world has known. In contrast to the other religions of the world, Islam defines religion itself as the very business of life, the very matter of spacetime, the very process of history, and the gift of Allah. Therefore, all these work together to constitute them. Islamic principles and teachings can provide realistic, fair and objective solutions to the prevention of individual, familial, social and international problems which are threatening the existence of human communities throughout the world.

Muslims cannot do anything without a jurisprudent ruling either by obligation, prohibition, legalisation, recommendation or abhorrence. Therefore, everything in a Muslim's life submits to and are gauged against these five jurisprudentially rulings, such that whatever comes to one's mind always has a jurisprudential verdict in Islam.

Regarding the hukm in Islamic Shariah, it consists of Hukm Taklifi (Defining Law) and Hukm Wadh'ie (Declaratory Law). Hukm Taklifi relates with the demand and option i.e. rights and duties. While Hukm Wadh'ie comprises things to be a cause (sabab), condition (shart), and impediment (mani').

Scope of Hukm Taklifi is always within the power and ability of mukallaf to perform or to abstain from performing it. This category is divided into two; (1). 'Azimah (Regularity) and (2) Rukhsah (Despensation). 'Azimah means all those regular commands of Shariah which have been primarily promulgated such as performing five daily prayers, fasting in Ramadhan, Giving zakah, Performing pilgrimage, and others. Meanwhile, Rukhsah is related with the demand would not be a reasonable one if the act is beyond the capability of the person. In this case, the latitude is given to a person under obligation in his action for an excuse due to unable to perform it.

In this case of a 33- year old nursing mother who complained of blood-stained breastmilk while expressing her breastmilk via mechanical breast pump falls under the rukhsah due to difficulty of isolating the blood-stained breastmilk. Basically, the blood that flows out from any part of the body is considered najasah (filth). However, small quantity of blood such as blood of mosquito, lizard, fly, etc is considered pure (not najasah) because it does not gush forth. Similarly blood-stained with flesh (of slaughtered animal) or breastmilk is being excused and pure. This is based on the qawa'id fiqhiyyah (legal maxim) of al-masyaqqah tajlib al-taysir (hardship begets facility). According to Imam alSuyuti, the criterion for hardship to beget facility is the condition in a very severe difficulty. This is a cause for ease and dispensation. Thus, the hardship to isolate the blood-stained breastmilk is among such difficulty. ${ }^{27}$

This is also based on the concept of 'Umum al-Balwa (Generality of the hardship): The difficulty of maintaining vigilance: this means the difficulty of avoiding something in worship and in other similar things. The blood-stained breastmilk sometimes untraceable due to some biological and mechanical factors. Therefore, the case of blood-stained breastmilk is allowable since it rarely happens, in small quantity, it does not gush forth, and there is study on its safety indicates no complication of its consumption. This 'umum al-balwa is safe as being 
proved by scientific medical evidence through breastmilk analysis which showed no evident of malignant cells. Nevertheless, the culture and sensitivity of the milk revealed insignificant of bacterial growth. The same goes to the ultrasound of the breast which showed changes related to lactation with no other abnormality seen. ${ }^{28}$

In the theory of Maqasid, Islam encourages breastfeeding as the best way for infant feeding which contains all the vitamins and nutrients especially in the first six month of life. This is the purpose of objectives of shar' to secure the interest (maslahah) of mankind pertaining to this world (dunya) and Hereafter (akhirah). For that maslahah, al-Quran indicates the significance of breastfeeding. ${ }^{29,30}$ For that Allah says:

Mothers may breastfeed their children two complete years for whoever wishes to complete the nursing [period]. Upon the father is the mothers' provision and their clothing according to what is acceptable. No person is charged with more than his capacity. No mother should be harmed through her child, and no father through his child. And upon the [father's] heir is [a duty] like that [of the father]. And if they both desire weaning through mutual consent from both of them and consultation, there is no blame upon either of them. And if you wish to have your children nursed by a substitute, there is no blame upon you as long as you give payment according to what is acceptable. And fear Allah and know that Allah is seeing of what you do. (alBaqarah: 233). ${ }^{31}$

\section{CONCLUSION}

This case highlights the uncommon problem but important in Muslim nursing mothers in terms of safety from medical and Islamic ruling perspectives. Awareness of the health care providers in dealing with such problem in nursing mothers is crucial in order to recognize the causal factor, to avoid unnecessary investigations, giving appropriate management and to allay concerns of the mothers. Islam allows this practice since its safety is clinically confirmed and it falls under the case of necessity for the sake of human interest and removing the hardship.

\section{References}

1. Merlob P, Aloni R, Prager H, Mor N, Litwin A. Blood-stained maternal milk: prevalence, characteristics and counselling. Eur J Obstet Gynecol Reprod Biol. 1990;35(2-3):153-157. doi:10.1016/0028-2243(90)90156-U.

2. Lawrence RA. Breastfeeding: A Guide for the Medical Profession. Sixth edit. Mosby, St. Louis; 2005.

3. N. M. Breastfeeding Answers Made Simple: A Guide for Helping Mothers. First edit. Hale Publisher; 2010.

4. Amir LH. ABM Clinical Protocol \#4: Mastitis, Revised March 2014. Breastfeed Med. 2014;9(5):239-243. doi:10.1089/bfm.2014.9984.
5. Fetherston C. Risk factors for Lactational Mastitis. J Hum Lact. 1998.

6. World Health Organization. Mastitis - Causes and Management. World Heal Organ. 2000:1-44.

7. Kvist LJ, Larsson BW, Hall-Lord ML, Steen A, Schalen $\mathrm{C}$. The role of bacteria in lactational mastitis and some considerations of the use of antibiotic treatment. IntBreastfeedJ. 2008;3(1746-4358 (Electronic)):6. doi:10.1186/1746-4358-3-6.

8. Faridi MMA, Dewan P, Batra P. Rusty pipe syndrome: counselling a key intervention. Breastfeed Rev. 2013;21(3):27-30.

9. Thota U, Machiraju VM, Jampana VR. Rusty pipe syndrome : A case report. Sci Res. 2013;5(1):157-158.

10. Mansel R, Webster D SH. Benign Disorders and Diseases of the Breast. Saunders Elsevier; 2009.

11. Santos KJ da S, Santana GS, Vieira T de O, Santos CA de ST, Giugliani ERJ, Vieira GO. Prevalence and factors associated with cracked nipples in the first month postpartum. BMC Pregnancy Childbirth. 2016;16(1):209. doi:10.1186/s12884-016-0999-4.

12. Centuori S, Burmaz T, Ronfani L, Fragiacomo M, Quintero S, Pavan C et al. Nipple care, sore nipples, and breastfeeding: a randomized trial. J Hum Lact. 1999:15-20.

13. Foxman B, Schwartz K, Looman SJ. Breastfeeding Practices And Lactation Mastitis. 1994;38(5).

14. Cacala S. Breast conditions during pregnancy and lactation. In: Glob. Libr. Women's Med. Vol 28. ; 2010:28-30. doi:10.3843.

15. Al Sarakbi W, Worku D, Escobar PF, Mokbel K. Breast papillomas: current management with a focus on a new diagnostic and therapeutic modality. Int Semin Surg Oncol. 2006;3:1. doi:10.1186/1477-7800-3-1.

16. Helewa M, Levesque P, Provencher D. Breast cancer, pregnancy, and breastfeeding. J Obstet Gynaecol Canada. 2002;(111):1-8. http://europepmc.org/abstract/MED/12196882.

17. Goldsmith HS. Milk-rejection sign of breast cancer. Am J Surg. 1974;127(3):280-281. doi:10.1016/0002-9610(74)90032-4.

18. Petok ES. Breast cancer and breastfeeding: Five cases. J Hum Lact. 1995;11:205-209.

19. Saber A, Dardik H, Ibrahim IM WF. The milk rejection sign:a nature tumour marker. $A m$ Surg. 1996;62(998-9).

20. http: / / forums.llli.org/showthread.php?t1/418619.

21.http://parenting.ivillage.com/baby/bbreastfeed $10,3 \times 3 g, 00 . h t m l$.

22. http://www.pregnancy.org/question/helpthere-blood-my-milk.

23. Phelps MM, Bedard WS, Henry E, et al. Attitudes of NICU professionals regarding feeding bloodtinged colostrum or milk. J Perinatol. 2009;29(2):119-123. doi:10.1038/jp.2008.188.

24. Barco I, Vidal MC, Barco J, et al. Blood-Stained Colostrum and Human Milk during Pregnancy and Early Lactation. J Hum Lact. 2014;30(4):413-415. 
doi:10.1177/0890334414539041.

25. Lawrence RA. Breastfeeding: A Guide for the Medical Profession. 6th Edition. 6th ed. Mosby; 2005.

26. Rebecca Mannel, Patricia J. Martins and MW. The Core Curriculum for Lactation Consultant Practice. Second. Jones and Bartlett Publisher

27. Al-Suyuti . Al-Ashbah Wa Al-Naza'ir,. Dar alKutub al-Ilmiyyah, Beirut; 1996.

28. Al-Syirbini al-Khatib. Al-Iqna' Fi Hal Alfaz Abi Syuja'. Jil.2. Dar al-Kutub al-'Ilmiyyah, Beirut; 1996.

29. Al-Malibariy Z. Fath Al-Mu'in, Terj. Drs. Aliy As'ad. Klang: Klang Book Centre; 1988.

30. Al-Qurtubi. Al-Jami' Li Ahkam al-Qur'an. Jil. 2. Dar al-Fikr , Beirut; 1995.

31. The Noble Quran 2: 233 